\title{
Indicaciones y Valoración Clínica del Urocultivo y Coprocultivo
}

\section{Indications and Clinical Evaluation of Urine culture and Stool}

${ }^{1}$ Dra. Carmen Marín, ${ }^{2}$ Dra. Aurelia Taboada, ${ }^{2}$ Dr. Gustavo Benítez. ${ }^{1}$ Hospital de Policía Rigoberto Caballero - ${ }^{2}$ Instituto de Medicina Tropical

Objetivo: Evaluar la relevancia del uro y coprocultivo en la práctica clínica frecuente. Estrategia de búsqueda y selección de estudios: Se ha realizado una revisión bibliográfica en las bases de datos on-line Elsevier-Doyma y PubMed, de los artículos y guías de práctica clínica publicadas sobre este tema priorizando los trabajos realizados en América Latina. Selección de estudios y de datos: En la revisión se han incluido guías de la Sociedad Americana de Enfermedades Infecciosas (IDSA), manuales y guías de la Sociedad Española de Enfermedades Infecciosas, y los últimos artículos originales sobre este tema publicados en la región. Resultados: Escherichia coli continúa siendo el agente causal más frecuente tanto en urocultivo como en coprocultivo. En nuestro Hospital, han aumentado de forma importante las resistencias a antimicrobianos en especial a quinolonas. Conclusiones: La mayoría de los antibióticos utilizados como primera línea en la terapia empírica presentan elevados porcentajes de resistencias. En nuestro Hospital el antibiótico empírico de elección en infecciones urinarias fue levofloxacina en un 34,4\% y ciprofloxacina en un $42 \%$. En cuanto al coprocultivo la mayor resistencia presenta Eritromicina $y$ Levofloxacina con $87,5 \%$, seguido de Ampicilina con $76 \%$ de resistencia. Palabras clave: infección urinaria, bacteriuria asintomática, tratamiento empírico y betalactamasas de espectro extendido.

Abstract

Aim: Evaluate the relevance of the urine culture and stool culture in common clinical practice.
Search strategy and selection of studies: We performed a literature review on databases online Elsevier-Doyma and PubMed, articles and clinical practice 
guidelines published on this subject prioritizing work in Latin America.

Study selection and data: The review included guides Infectious Diseases Society of America (IDSA), manuals and guides the Spanish Society of Infectious Diseases, and the last original published articles on this topic in the region.

Results: Escherichia coli remains the most prevalent in both urine culture and coprocultivo causal agent. In our hospital, they have increased significantly the resistance to antibiotics especially quinolones.

Conclusions: Most of the antibiotics used as first-line empiric therapy have high percentages of resistance. In our Hospital empirical antibiotic of choice in urinary tract infections was $34.4 \%$ levofloxacin and ciprofloxacin by $42 \%$. Regarding coprocultivo presents greater resistance to erythromycin and Levofloxacin 87.5\%, followed by $76 \%$ Ampicillin resistance

Key words: urinary tract infection, asymptomatic bacteriuria, empirical treatment and extended-spectrum betalactamase.

\section{Introducción}

El urocultivo es el cultivo de orina para diagnosticar infección sintomática del tracto urinario o infección asintomática (bacteriuria asintomática) en pacientes con riesgo de infección.

Está basada en la presencia de un número significativo de bacterias (generalmente $>100.000$ bacterias/ml.) La piuria, junto con la bacteriuria, es un dato muy importante para el diagnóstico de infección del tracto urinario, ya que prácticamente está presente en todas las infecciones urinarias. Una excepción es la bacteriuria asintomática en la que la piuria puede estar ausente.

Por su parte, las enfermedades diarreicas constituyen un problema de salud pública. Sin embargo, muchas de estas enfermedades no son notificadas, ya sea porque en su mayoría son autolimitadas y no ameritan la consulta al médico, o porque no son reportadas oportunamente por el personal de salud (subregistro). Su etiología infecciosa es diversa, pudiendo ser producida por bacterias, virus, parásitos y hongos (1).

Cualquier intento por aislar bacterias patógenas de las heces implica la separación de las especies patógenas, usualmente a través del uso de medios selectivos, diferenciales y de cultivos de pre-enriquecimiento. El diagnóstico bacteriológico de las infecciones entéricas se realiza de acuerdo a su patogenia. En las infecciones diarreicas se utiliza el coprocultivo, pero una vez que las bacterias invaden el torrente sanguíneo, el diagnóstico debe hacerse además, por el hemocultivo y el estudio serológico.

Tanto el urocultivo como el coprocultivo son métodos tradicionalmente realizados en el laboratorio de microbiología clínica que siguen manteniendo su vigencia y utilidad, no sólo por ser sencillos y baratos, sino porque además establecen un diagnóstico de certeza identificando al agente causal, permiten conocer la sensibilidad de dichos patógenos a los antimicrobianos y confirman la curación bacteriológica (1).

La etiología de las infecciones del tracto urinario se ha considerado durante décadas bien establecidas y por tanto de escaso interés. Un análisis de las series más recientemente publicadas permite comprobar que Escherichia coli sigue siendo el uropatógeno predominantemente 
aislado, seguido en un orden variable por Proteus mirabilis, Enterococcus faecalis, Klebsiella pneumoniae, Pseudomonas aeruginosa, Enterobacter cloacae, Streptococcus agalactiae, Staphylococcus saprophyticus, Serratia marcescens y Morganella morganii (2).

Por otra parte, la diarrea es uno de los cinco principales problemas de salud pública en el mundo. Es ampliamente reconocida la importancia de determinar su etiología, establecer el diagnóstico y los tratamientos más apropiados, para evitarlos efectos indeseables como deshidratación y la desnutrición.

\section{Materiales y Métodos}

Estrategia de búsqueda y selección de estudios: Se ha realizado una revisión bibliográfica en las bases de datos on-line PubMed, de los artículos y guías de práctica clínica publicadas sobre este tema priorizando los trabajos realizados en Latinoamérica.

En cuanto a la recolección de datos, se procedió a la revisión de la base de datos WHONET $®$ del Laboratorio de Bacteriología con el fin de identificar todas las muestras positivas de urocultivo y coprocultivo en pacientes adultos internados en el IMT durante el periodo comprendido entre enero de 2011 y diciembre de 2013.

Selección de estudios y de datos: En la revisión se han incluido guías de la Sociedad Americana de Enfermedades Infecciosas (IDSA), manuales y guías de la Sociedad Española de Enfermedades Infecciosas, y los últimos artículos originales sobre este tema publicados en nuestro país.

Definición de Variables: Se definió urocultivo y coprocultivo positivo cuando se aisló algún microorganismo patógeno con recuento significativo con antibiograma informado.

Análisis estadísticos: Para el análisis de datos se recurrió al programa EpiInfo $\AA$ para Windows ${ }^{\circledR}$ 3.4.3 Centers for Disease Control and Prevention, Atlanta, Georgia, United States of America).

Para la comparación de proporciones se utilizó $X^{2}$. Se consideró estadísticamente significativo un valor $p<0,05$.

\section{Resultados}

Se han encontrado un total de 418 aislamientos positivos de cultivos de orina, y 54 aislamientos positivos de heces.

Las características demográficas de los pacientes se muestran en la tabla 1 , viendo un predominio femenino del $60 \%(n=201)$ con un promedio de edad de 49 años versus el $40 \%$ de los hombres con igual promedio de edad.

En ambos sexos, el grupo etario que más se ve afectado por las infecciones urinarias es la de 36 a 59 años con el 45,7 y $37,1 \%$ en el sexo femenino y masculino, respectivamente (OR 1,5 [0,9-2,3] RR 1,2 [0,9-1,64]) hallando así mayor riesgo de infección en las mujeres que en varones ( $p$ $=0,06)$.

El total de estudios de urocultivo nos arroja un valor de 4.065 con un promedio anual de 1.392 muestras, observamos un aumento en los casos en el periodo de julio a octubre, el porcentaje de retorno en urocultivos de nuestra serie de estudio nos da un porcentaje de retorno del $10 \%$ con un aumento desde el 2011 al $2013(8.7 \%$ $9.9 \% \quad-\quad 11.9 \%$ respectivamente), coincidente con otros autores (Gráfico 1) (3) 
Tabla 1. Rango etario según sexo de los pacientes con infección urinaria aislados en el Laboratorio de Bacteriología del IMT. Años 2011 - 2013

\begin{tabular}{lrc}
\hline \multicolumn{1}{c}{$\begin{array}{c}\text { Características } \\
\text { demográficas }\end{array}$} & $\mathbf{n = 4 1 8}$ & \% \\
\hline Femenino & 243 & 58.1 \\
$<35$ años & 68 & 28.0 \\
$36-59$ años & 111 & 45.7 \\
>50 años & 64 & 26.3 \\
Masculino & 175 & 41.9 \\
$<35$ años & 47 & 26.9 \\
$36-59$ años & 65 & 37.1 \\
$>50$ años & 63 & 36.0 \\
\hline
\end{tabular}

Grafico 1. Retorno de muestras positivas de Urocultivo y Coprocultivo aislados en el Laboratorio de Bacteriología del IMT. Años 2011 - 2013

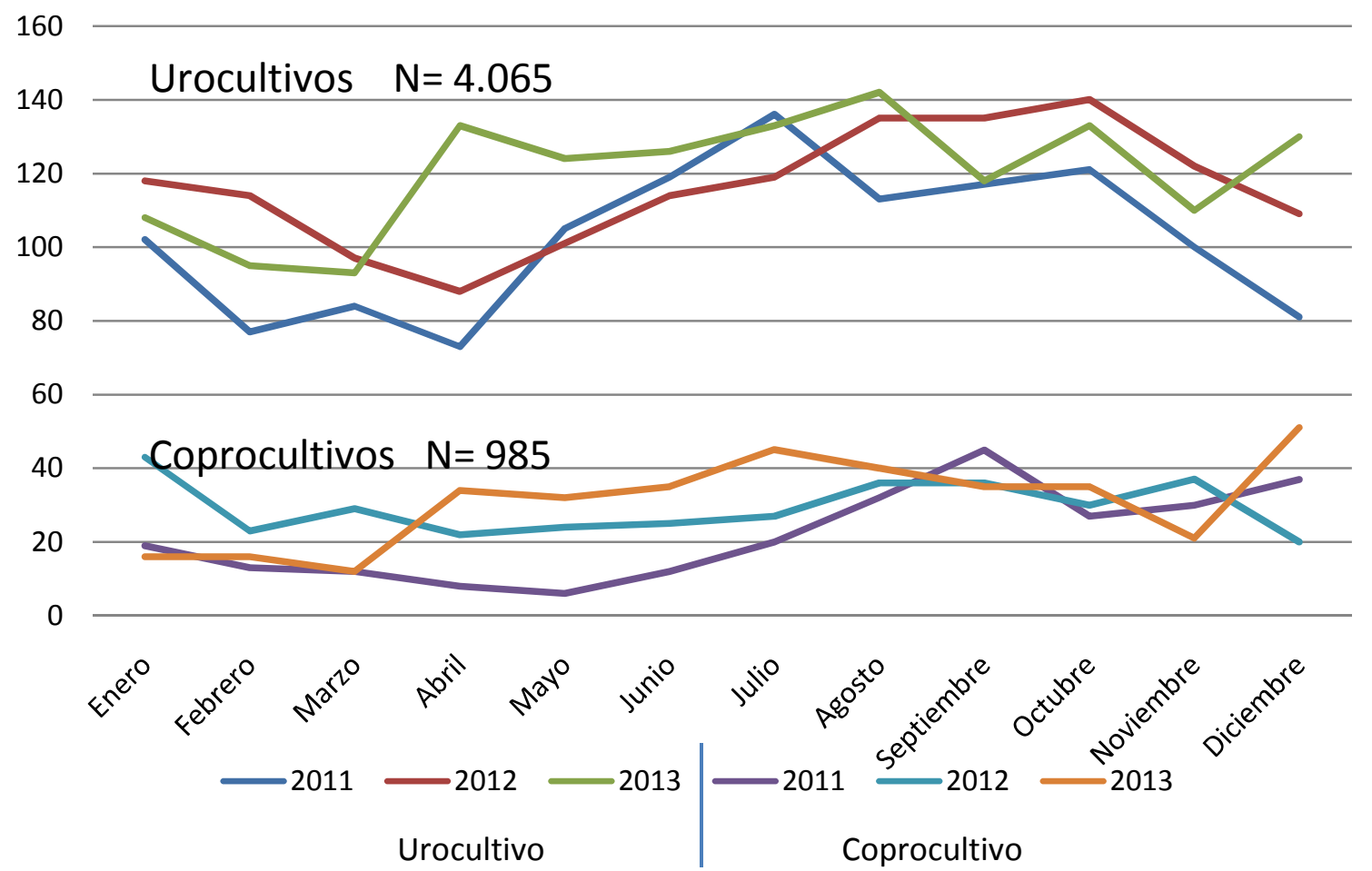

En cuanto a los aislamientos de tendencia a la disminución del porcentaje coprocultivos, la tasa de retorno es menor, de retorno $(6.5 \%-6.3 \%-4 \%$ con un promedio de $6 \%$, a diferencia de los respectivamente) (Grafico 2).

aislamientos de coprocultivo hay una 
Grafico 2. Aislamientos positivos de Coprocultivo aislados en el Laboratorio de Bacteriología del IMT. Años 2011 - 2013

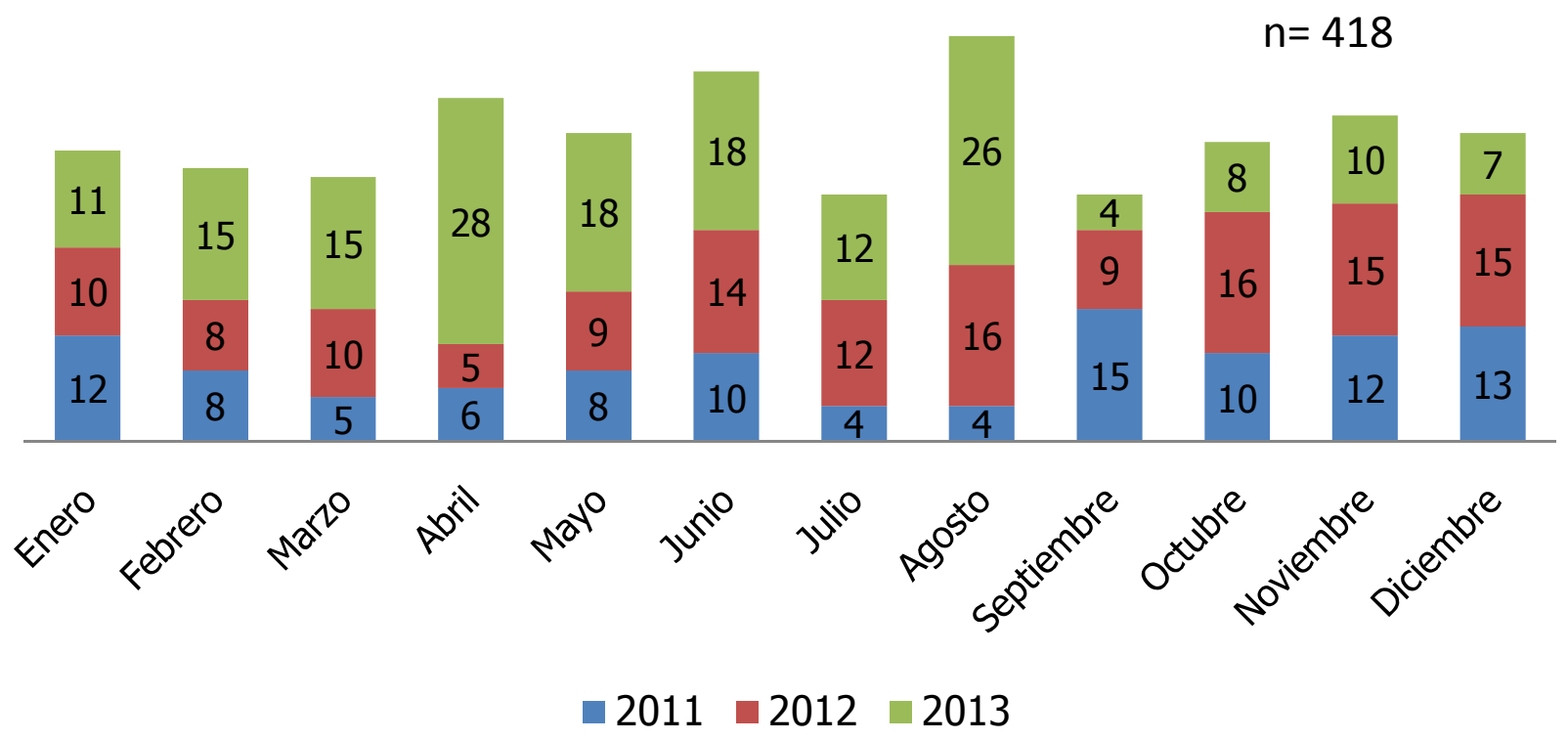

En cuanto a los aislamientos de urocultivos (Grafico 3) positivos observamos que los picos ocurrieron en los meses entre abril y agosto con el $45 \%$ del total de casos, no hemos encontrado artículos referentes a la periodicidad 0 estacionalidad de las infecciones urinarias con lo que no podemos hacer una correlación directa o asociar este factor a otros factores y la bibliografía consultada, no hace referencia a este factor

\section{Grafico 3. Aislamientos positivos de Urocultivos en el Laboratorio de Bacteriología del IMT. Años 2011 - 2013}

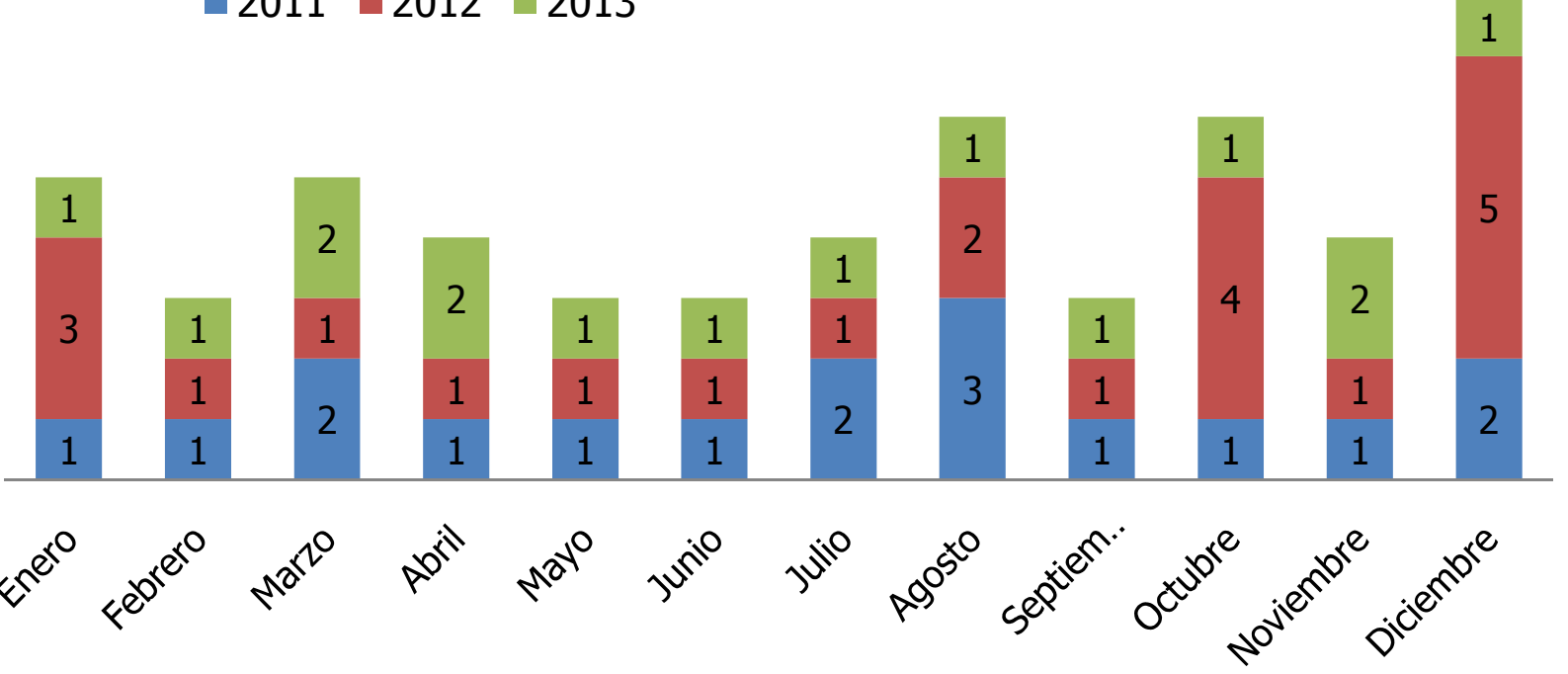




\section{Grafico 4. Agentes etiológicos de infecciones urinarias adquiridas en la comunidad.}

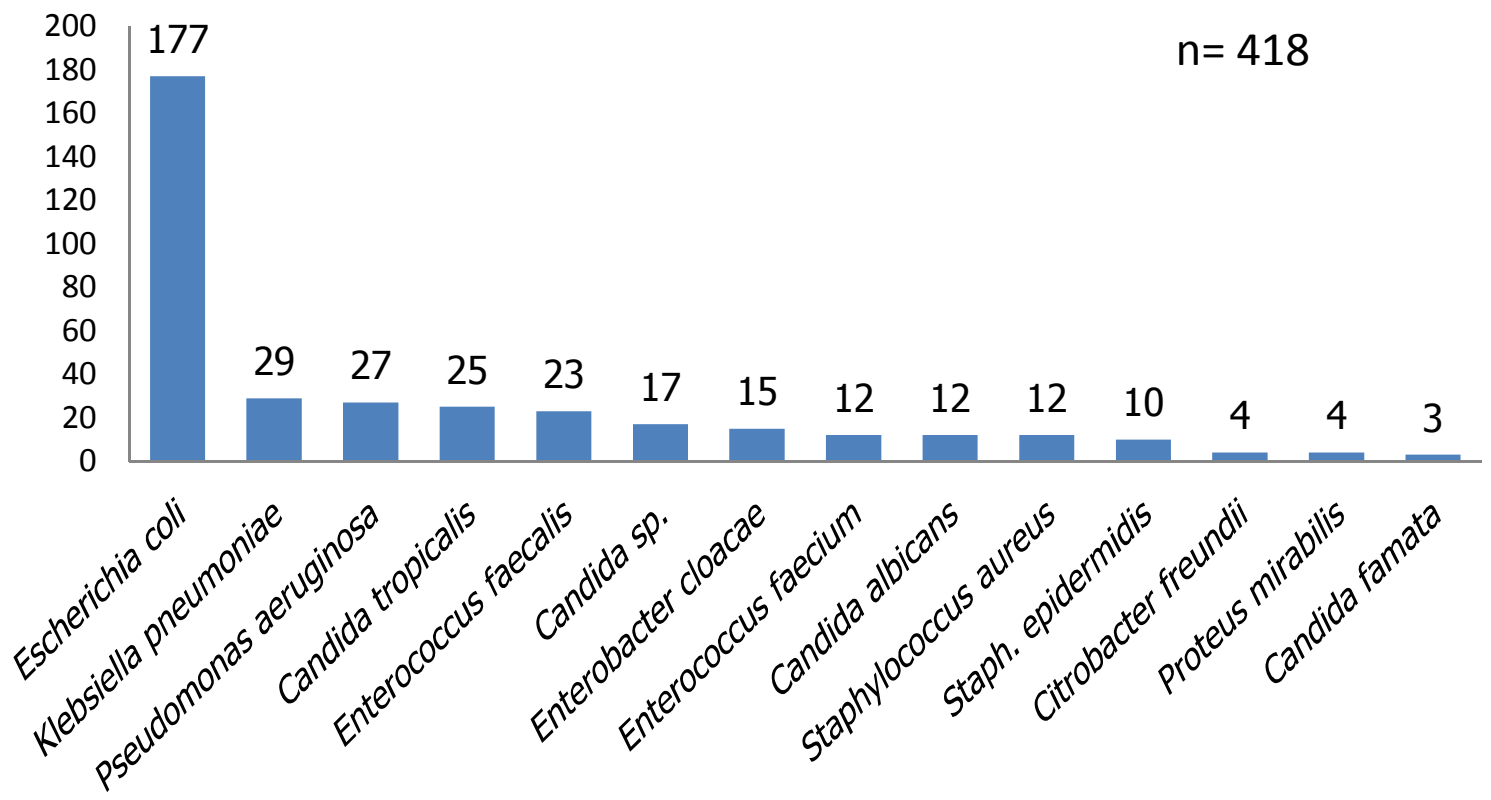

En cuanto a las infecciones gastrointestinales, es un poco más marcada la prevalencia de aislamientos positivos en meses de calor de octubre a enero, asociado a las infecciones causadas por el agua. En general, las frecuencias de aislamiento que suelen observarse son altamente dependientes del tipo de unidades con que cuenta el hospital, al ser un hospital de referencia para enfermedades infecciosas el margen de recuperación no es elevado.

Tal y como observamos en este trabajo, el estudio de Prats (4), demuestra un aumento de casos en épocas de inicio del calor, agosto hasta enero

Varios estudios descriptivos realizados en nuestro país en los últimos años continúan situando a $E$. coli como principal agente etiológico de las ITU (60 - 93,2\%), y esto se refleja en nuestro trabajo con un aislamiento de 177 muestras correspondientes al $42 \%$, un tanto menor a lo reportado por otros autores, pero creemos es debido al retorno bacteriológico deficiente.
El segundo y tercer lugar siguen siendo las bacterias Gram negativas las predominantes, totalizando el $61 \%$ de los aislamientos en infecciones urinarias, $K$. pneumoniae 7 \% y $P$. aeruginosa $6 \%$ ) estos datos son iguales a los reportados por otros autores (Klebsiella spp. 6,9 - 9,9; P. aeruginosa3-6,3\%) (2-5).

Otro germen frecuente es Enterococcus spp. que representa el $5 \%$ de los aislamientos, menor a lo reportado por otros autores para los que representa el 9.7 a $15.4 \%$, $S$. aureus es un germen de bajo aislamiento, tanto para nuestra serie como para otros autores rondan los $3(2,4-6)$ (Grafico 4).

Andreu et al han realizado un estudio multicéntrico, analizaron 3.055 infecciones urinarias bajas adquiridas en la comunidad, el estudio se realizó en 15 laboratorios de 9 Comunidades autónomas de España. El hecho de que $S$. saprophyticus y Proteus mirabilis no se encuentren entre los más frecuentes, puede deberse a que estos gérmenes suelen ocasionar ITU no complicada en mujeres jóvenes dónde el 
estudio microbiológico no suele estar indicado, ambos gérmenes representan el $1 \%$ del total de aislamientos en nuestros pacientes (3).

La resistencia antimicrobiana de los uropatógenos constituye un problema importante que conlleva dificultades para el tratamiento de todos los procesos infecciosos, incluidos los urinarios.

A nivel general, nuestro perfil de resistencia bacteriana se presenta en el gráfico 5 , con valores de más del $50 \%$ en trimetroprim sulfametoxazol, eritromicina y ampicilina, que si bien la etiología de la ITU no ha variado significativamente, el perfil antibiótico descrito en estudios tanto intrahospitalarios como a nivel nacional realizados en la última década muestran tasas elevadas de resistencia por encima del $10-20 \%$, estos valores desaconsejan la utilización de fármacos que hasta ahora se han utilizado como primera línea de tratamiento como terapia empírica (7).

\section{Grafico 5. Resistencia antimicrobiana mayor al $50 \%$ de gérmenes aislados en urocultivo}

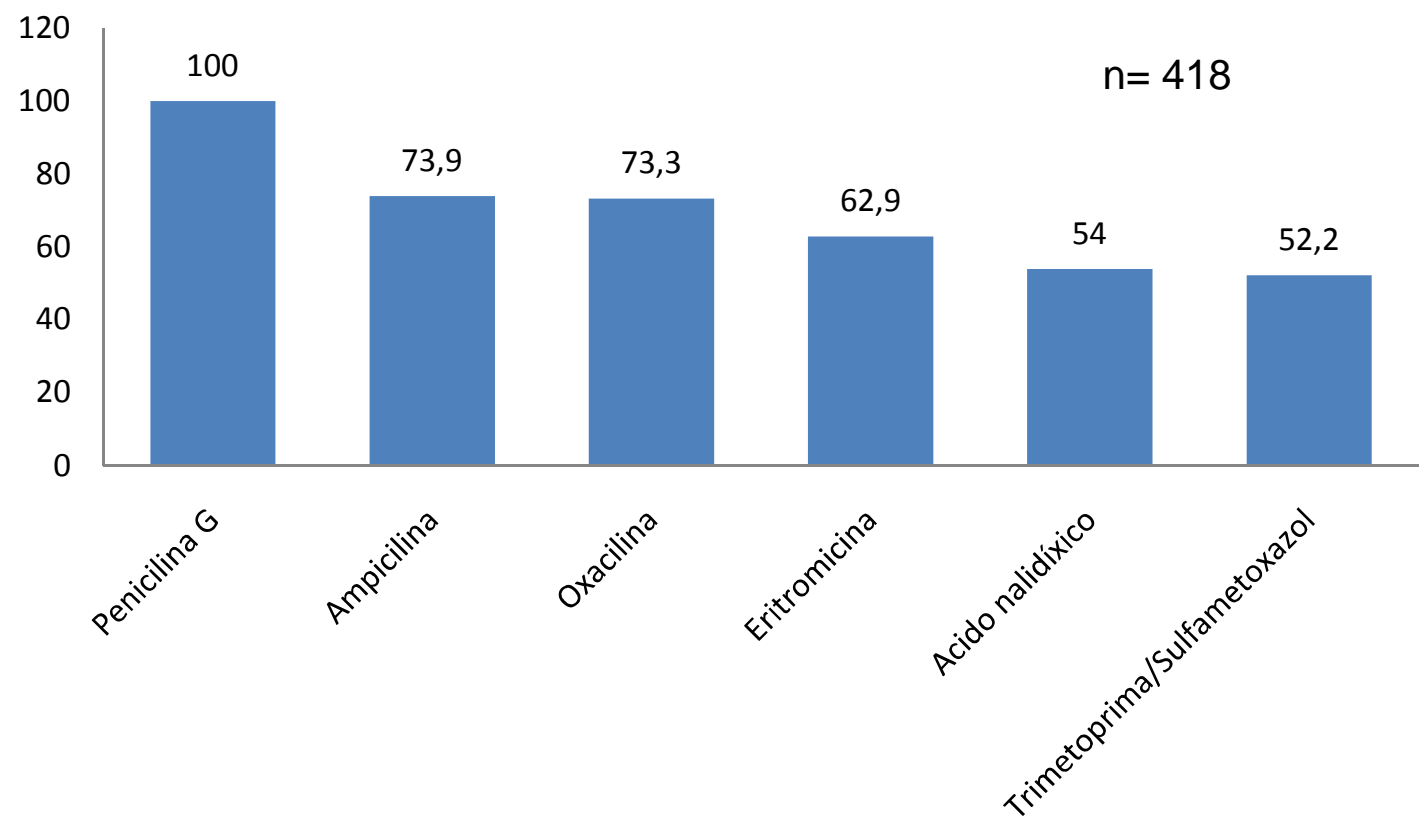

En un estudio descriptivo realizado en nuestro hospital en 2009, se recoge que el antibiótico más utilizado para tratar esta patología es la ciprofloxacina $(42,2 \%)$, seguida de amoxicilina clavulánico (34,4\%), ceftriaxona $(6,9 \%)$ y trimetroprim sulfametoxazol $(52,2 \%)$. Las mayores tasas de resistencias que se encontraron actualmente fue la ampicilina $73,9 \%$, seguidas de quinolonas $(42,2 \%$ ciprofloxacina, 34,4 \% levofloxacina) (8).
En nuestro hospital los antibióticos con mayor sensibilidad fueron imipenem (95 $\%)$, nitrofurantoína (81\%) y amoxicilinaclavulánico (66\%), todos estos datos coinciden con el trabajo realizado por Monroy et al (9).

Si nos centramos en la sensibilidades de $E$. coli, el perfil es similar, con resistencias a ampicilina de 73,9\%, a ciprofloxacina $45,2 \%$, amoxicilina 
clavulánico de $20 \%$, cotrimoxazol $52.2 \%$ y cefuroxima $7.1 \%$.

En un estudio multicéntrico realizado sólo en mujeres con cistitis agudas no complicadas con urocultivo positivo las resistencias que mostró $E$. coli fueron principalmente frente a ampicilina (52.1 $\%)$, cotrimoxazol (26\%) y quinolonas (18 $\%)$, mientras que las resistencias a amoxicilina clavulánico, cefuroxima axetilo y fosfomicina fueron inferiores al $3 \%$, con aumento significativo para cada una de ellas en mujeres mayores de 65 años. La resistencia a quinolonas además se relacionó con su consumo previo, y varió entre comunidades con tasas mayores en el sur y el este del país (16.6 \%) (10).
Otro problema importante es el aumento de prevalencia de cepas productoras de betalactamasas de espectro extendido. La bacteriemia por $E$. coli BLEE se asocia a mayor mortalidad y dificultad de tratamiento, su foco más frecuente es el urinario.

En los estudios comentados anteriormente se describen porcentajes de E. coli BLEE del $5,2 \%$ al $6,7 \%$, con una diferencia no significativa de un $11,8 \%$ en los pacientes procedentes de residencia y $5 \%$ en el resto (3).

\section{Tabla 2. Rango etario según sexo de los pacientes con coprocultivo positivo aislados en el Laboratorio de Bacteriología del IMT. Años 2011 - 2013}

\begin{tabular}{lrr} 
& $\mathbf{n = 5 4}$ & $\mathbf{\%}$ \\
\hline Femenino & 21 & 38.9 \\
$<35$ años & 8 & 3.3 \\
$36-59$ años & 7 & 2.9 \\
$>50$ años & 6 & 2.5 \\
\hline Masculino & 33 & 61.1 \\
$<35$ años & 17 & 9.7 \\
$36-59$ años & 11 & 6.3 \\
$>50$ años & 5 & 2.9 \\
\hline
\end{tabular}

La distribución de casos en los pacientes con coprocultivo positivo no muestra una marcada tendencia al rango etario afectada por infecciones gastrointestinales, y si una leve tendencia al sexo masculino, sin valores estadísticamente significativos $(p=0,02)$ (Tabla 2).

Los aislamientos de coprocultivo correspondieron en su totalidad a bacterias Gram negativas, con predominio de enterobacterias como $E$. coli predominante con el $13 \%(7 / 54)$ y $K$. pneumoniae con el
9\% (5/54), seguido de Salmonella sp. con el $9 \%$, clasificada como bacteria invasora junto a la Shigella spp (11) (Gráfico 6).

Más del $90 \%$ de las diarreas agudas son autolimitadas por lo que no se aconseja tratamiento antibiótico empírico. El tratamiento con antibióticos de forma empírica estaría indicado en pacientes con diarrea moderada - grave. El tratamiento de elección es ciprofloxacina, con un $43 \%$ de resistencia encontrada en nuestra serie $y$, como alternativa, cotrimoxazol con $61 \%$ de resistencia (Gráfico 7). 


\section{Grafico 6. Agentes etiológicos aislados de coprocultivos en el Laboratorio de}

\section{Bacteriología del IMT. Años 2011 - 2013}

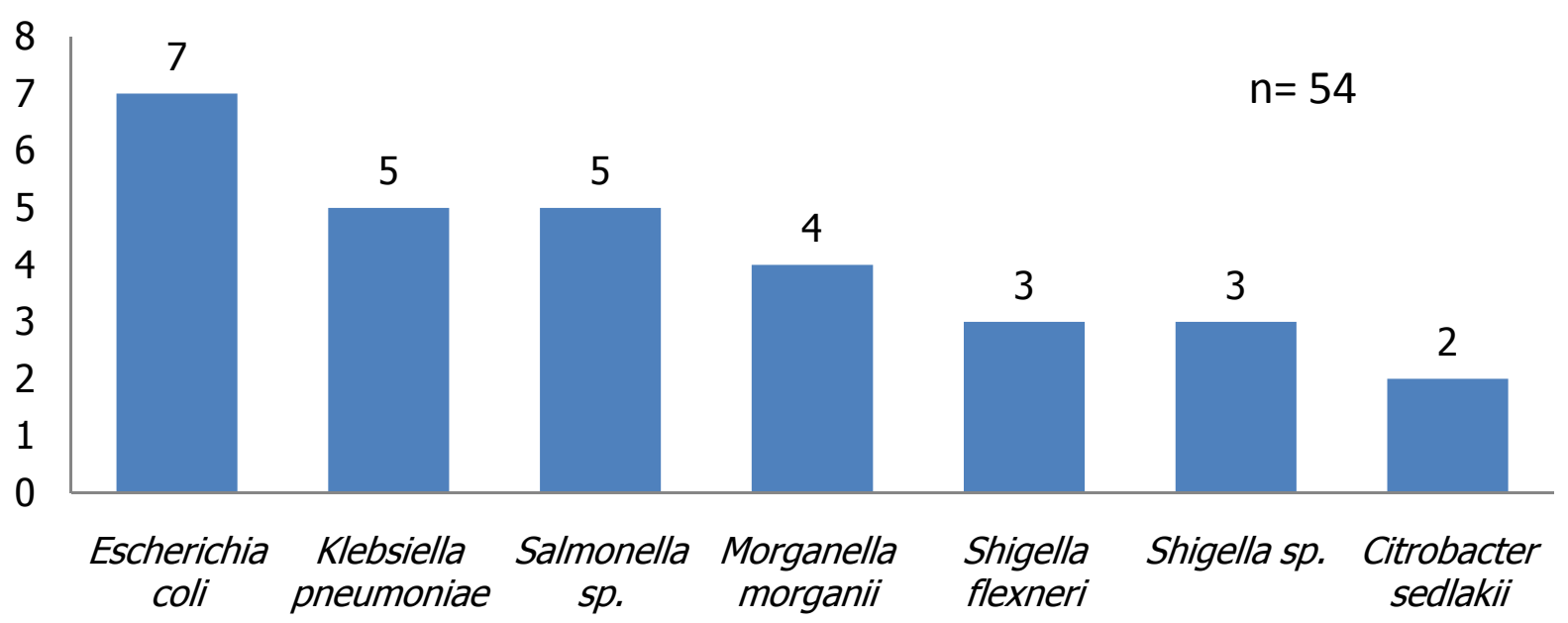

\section{Grafico 7. Resistencia antimicrobiana de gérmenes aislados en coprocultivo en el Laboratorio de Bacteriología del IMT. Años 2011 - 2013}

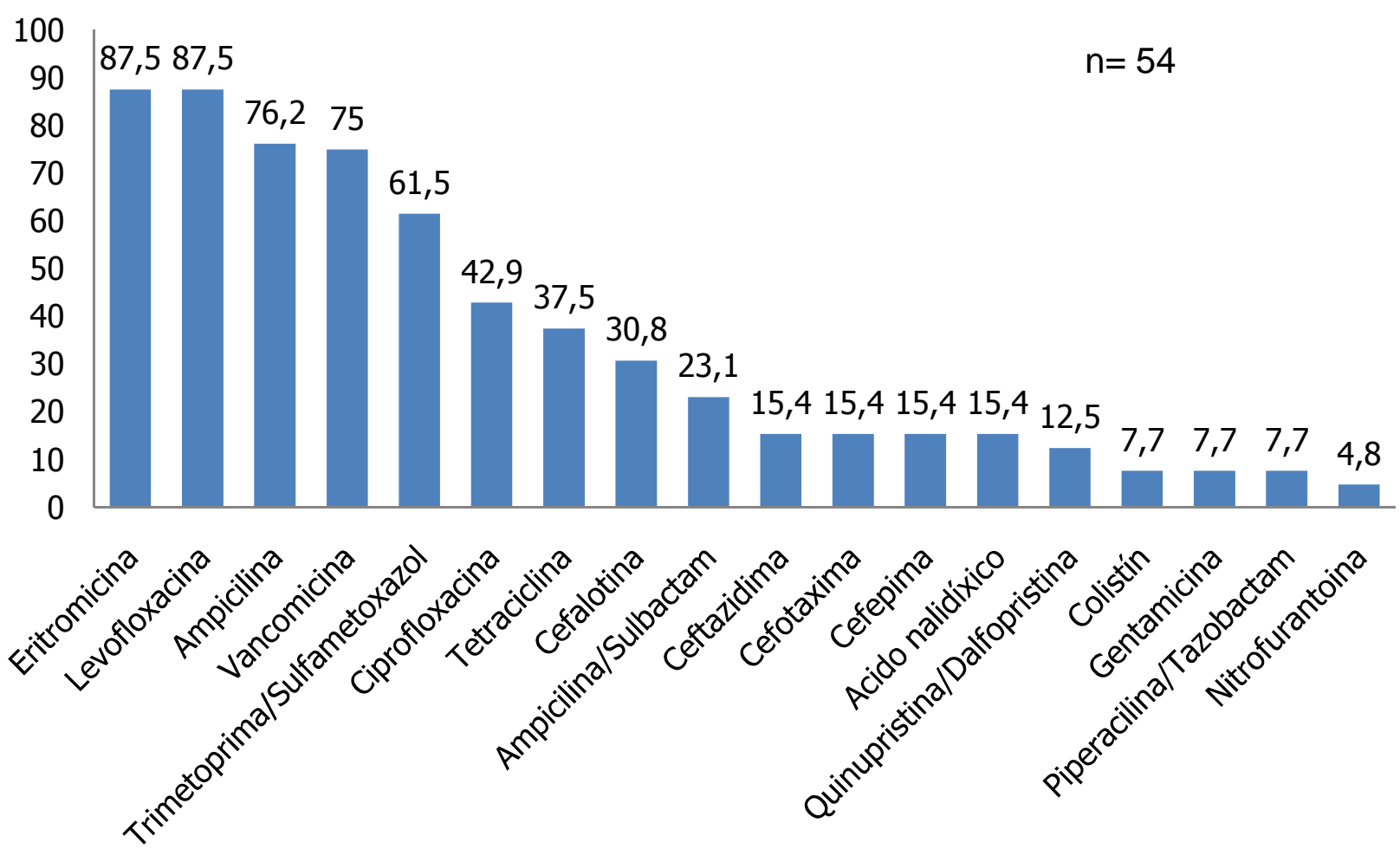

Las quinolonas son efectivas contra una gran variedad de patógenos bacterianos como Shigella, Salmonella, Yersinia y Aeromonas. Cuando el tratamiento antibiótico es correcto acorta la duración entre 1 y 3 días, mejorando de forma rápida los síntomas acompañantes (fiebre, tenesmo y la excreción de microorganismos). 
Debido a que se puede favorecer el aumento de portadores crónicos y a la mayor probabilidad de recurrencia, la gastroenteritis por Salmonella sólo se trata en personas con inmunosupresión, de edad avanzada, con enfermedades asociadas graves o con diarrea grave

\section{Conclusión}

La revisión bibliográfica realizada nos lleva a confirmar el cambio en las sensibilidades de los gérmenes más habituales en esta patología, con aparición de cepas multirresistentes, no solo a nivel regional, sino a nivel nacional, tal y como vemos en nuestro hospital con respecto a trabajos realizados en años anteriores.

Las infecciones urinarias mantienen un claro predominio en mujeres, y dentro del rango etario de 36 años y las infecciones intestinales se presentaron preferentemente en varones menores de 35 años.

El porcentaje de retorno positivo de urocultivos aumentó $10 \%$ desde el 2011 al $2013(8,7 \%$ - 9,9 \% - 11,9 \% respectivamente), en cuanto a los aislamientos de coprocultivos, la tasa de retorno es menor, con un promedio de $6 \%$.

En cuanto a la estacionalidad, vemos que los picos de urocultivos positivos ocurrieron en los meses entre abril y agosto con el $45 \%$ del total de casos y en cuanto a las infecciones gastrointestinales, es un poco más marcada la prevalencia de aislamientos positivos en meses de calor de octubre a enero.

En ambos casos $E$. coli es el patógeno predominante con más del $50 \%$ de los aislamientos.

$\mathrm{Si}$ nos centramos en los datos obtenidos en nuestro Hospital, hablamos de una tasa de resistencia a ampicilina y oxacilina de un $73,9 \%$ y a eritromicina $62,9 \%$. Esto en el caso de las quinolonas está justificado por el uso excesivo que hemos realizado, levofloxacina fue el antibiótico empírico que más utilizamos para tratar esta patología.

Debemos recordar que es tan importante la elección del antimicrobiano como la indicación correcta de su uso. Cabe, destacar la ausencia de alternativas de tratamiento. Esto ha llevado al rescate de fármacos antiguos, con nuevas formulaciones más eficaces y mejor toleradas. Por lo tanto, debemos cuidar el arsenal terapéutico de que disponemos pues las alternativas a corto plazo son escasas.

En conclusión el bajo porcentaje de retorno positivo tanto de urocultivo como de coprocultivo, nos impulsa a tomar recaudos al momento de la toma de muestra correcta a fin de potenciar esta herramienta diagnóstica eficaz.

\section{Referencias}

1. Quesada, E., E. Galban, A. Cádiz,: Royano M, Correas M, Clavo J, Roiz MP, Sangrador A, Casado S. Infecciones del tracto urinario. Boletín de uso racional del medicamento. Servicios de Farmacia de Atención Primaria. Servicio Cántabro de Salud. 2007 no. 4.1987

2. Ochoa C, Eiros JM, Pérez C, Inglada L. y Grupo de Estudio de los Tratamientos Antibióticos Etiología infecciones urinarias y sensibilidad de uropatógenos. RevEspQuimioterap2005; Vol. $18\left(\mathrm{~N}^{\circ} 2\right)$

3. Andreu A, Cacho J, Coira A, Lepe JA. Diagnóstico microbiológico de las infecciones del tracto urinario. En: Procedimientos en microbiología clínica de la Sociedad Española de Enfermedades Infecciosas y Microbiología Clínica. Número14b, 2.a 
edición. Editores: Emilia Cercenado y Rafael Cantón 2010

4. Prats Pastor G, Mirelis Otero B, Muñoz Batet C, Rabella García N. Indicaciones del coprocultivo, aspectos prácticos. Medicine. 1998;7(74):3456-7

5. Florentin de Merech L., Lascurain de Arza A., Baez delandoux D. et al. Consenso de Infección Urinaria: Pautas de diagnóstico y tratamiento. Pediatr. (Asunción), abr. 2011, vol.38, no.1, p.68-72. ISSN 1683-9803

6. Soplan J, Fineberg $H$, Ferraro $M$ J, Rosemberg M. Value of stool cultures. Lancet. 1980; August: 413-17.

7. Andreu Domingo A. La infección del tracto urinario en la práctica clínica. Rev Clin Esp 2010;210:556-558.

8. Ortega, E. Taboada, A. Prevalencia de Infecciones Bacterianas por Gérmenes
Oportunistas o Comunes en PVVS. Rev. Inst. Med. Trop 2011;6(1):7-16

9. Monroy C, Mañas MD, Santamaría A, Clemente MI. Resistencia antibiótica en la infección del tracto urinario e identificación de los factores de riesgo asociados. Rev Clin Esp 2010;210: 599600

10. Gobernado M, Valdés L, Alós JI, GarcíaRey C, Dal-Ré R. Garcia de Lomas J. Antimicrobial susceptibility of clinical Escherichia coli isolates from uncomplicated cystitis in women over a 1 -year period in Spain. Rev Esp Quimioterap 2007;20:68-76

11. Casburn AC, Farthing MJC. Management of infectious diarrhoea. Gut. 2004; 53:296-305

Fecha de recepción: 18 de febrero de 2014

Fecha de aceptación: 13 de octubre de 2014

Solicitud de Sobretiros:

Dra. Carmen Marín

Servicio de Clínica Médica

Instituto de Medicina Tropical

gbenite@yahoo.com.ar 